\title{
The Effect of Carbon Dioxide on Fruiting and on the Degradation of a Cell-wall Glucan in Schizophyllum commune
}

\author{
By J. H. SIETSMA, D. RAST* AND J. G. H. WESSELS \\ Department of Developmental Plant Biology, Biological Centre, \\ University of Groningen, Haren, The Netherlands
}

(Received 2 May 1977)

\begin{abstract}
A concentration of $5 \%$ carbon dioxide in air prevents fruiting in Schizophyllum commune and at the same time prevents the breakdown of R-glucan [ $(\mathrm{I} \rightarrow 3)-\beta,(1 \rightarrow 6)-\beta$-glucan] in the wall which normally occurs during growth of the pilei. R-glucanase is produced as in cultures grown in air but cultures grown in $\mathrm{CO}_{2}$-enriched air form more of a water-soluble $(\mathrm{I} \rightarrow 3)-\beta,(\mathrm{I} \rightarrow 6)-\beta$-glucan (mucilage) and less $\mathrm{R}$-glucan. This R-glucan is more resistant to enzymic hydrolysis which may explain the decreased breakdown of $\mathrm{R}$-glucan in vivo. Since $R$-glucan degradation is required for growth of the pilei to occur, $\mathrm{CO}_{2}$ must indirectly inhibit growth of the pilei by changing the composition of the walls in the previously formed mycelium.
\end{abstract}

\section{INTRODUCTION}

In basidiomycetes an increase in the $\mathrm{CO}_{2}$ content of the ambient air impairs fruit body formation (Taber, 1966). The effect has been especially well studied in Agaricus bisporus (Tschierpe \& Sinden, 1964) where $\mathrm{CO}_{2}$ concentrations as low as about $0 . \mathrm{I} \%$ (v/v) cause a retardation of the onset of fruiting and a decrease in the number of primordia formed. In Schizophyllum commune, $5 \% \mathrm{CO}_{2}$ in air does not affect mycelial growth and mating but completely inhibits fruiting (Niederpruem, 1963). The biochemical basis of these $\mathrm{CO}_{2}$ effects remains to be established. For $A$. bisporus it has been suggested (Rast \& Bachofen, 1967; Bachofen \& Rast, I968) that inhibition of fruiting by $\mathrm{CO}_{2}$ is correlated with an impairment of the Krebs cycle activity produced in much the same way as was later proposed for self-inhibition of spore germination in this fungus (Rast et al., I976a,b), i.e. inhibition of succinate dehydrogenase by the carboxylation product oxaloacetate, thus creating a metabolic situation in which the carbon flow through the glycolytic and Krebs cycle pathways becomes restricted.

In dikaryons of $S$. commune, growth of the pilei takes place after exhaustion of the glucose in the medium and is accompanied by a decrease in the wall polysaccharide R-glucan in the vegetative mycelium and stunted fruit bodies (Wessels, 1965). The R-glucan, a ( $1 \rightarrow 3$ )- $\beta$, $(\mathrm{I} \rightarrow 6)$ - $\beta$-linked alkali-insoluble glucan that occurs in close association with chitin in the wall (Sietsma \& Wessels, 1977), is degraded by R-glucanase, the activity of which increases after glucose exhaustion (Wessels, 1966; Wessels \& Niederpruem, 1967). Mobilization of endogenous reserves during fruit body expansion, including degradation of wall polysaccharides, has also been demonstrated in the agaric Flammulina velutipes (Kitamoto \& Gruen, 1976).

The present study was undertaken to see if the effect of $\mathrm{CO}_{2}$ on fruiting in $S$. commune is related to an inhibition of $\mathbf{R}$-glucan degradation.

* Present address: Institute of Plant Biology, University of Zürich, Zürich, Switzerland. 


\section{METHODS}

Organism and growth conditions. A dikaryon of Schizophyllum commune was constituted by mating strains $699(A+1 B+1)$ and $845(A 51 B 51)$. A macerate of the dikaryon was inoculated into 11 Erlenmeyer flasks containing $100 \mathrm{~g}$ sand and $30 \mathrm{ml}$ minimal medium (Wessels, 1965). The cultures, in triplicate, were incubated at $24{ }^{\circ} \mathrm{C}$ under continuous illumination and were continuously flushed with air or air containing $5 \% \mathrm{CO}_{2}$ at $40 \mathrm{~h} \mathrm{~h}^{-1}$. In some experiments, designed to study the effect of $\mathrm{CO}_{2}$ on morphology and not involving chemical determinations, agar plates were inoculated with a macerate of the dikaryon and incubated in an atmosphere of $\mathrm{CO}_{2}$-free air (KOH trap) or air containing $5 \% \mathrm{CO}_{2}$.

Chemical analysis. Mycelium and medium were collected from each culture by carefully decanting the mycelium from the sand on a filter and washing both the mycelium and the sand with water. The washwater containing the medium and excreted materials was made up to a known volume and used for the determination of residual glucose (with the glucostat reagent; Worthington Biochemical Corp.), polysaccharide (as anthrone-positive material minus the glucose content) and R-glucanase activity (see below). The washed mycelium was fragmented by passing it through an X-press (Biotec, Stockholm, Sweden) and walls were prepared as described previously (Wessels \& Marchant, 1974). The mucilage and the various wall components (Wessels et al., 1972; Sietsma \& Wessels, 1977) were then extracted and quantified.

Mucilage, a $(1 \rightarrow 3)-\beta,(I \rightarrow 6)-\beta$-glucan excreted into the medium, was determined as the sum of the glucan excreted into the medium and the glucan dissolving when the hyphae were fragmented with the X-press. Thus these measurements also included other water-soluble glucans, e.g. glycogen. However, the amount of glycogen was small since $\beta$-amylase [free of $(\mathrm{I} \rightarrow 3)-\beta$-glucanase] digested less than $\mathrm{I} \%$ of the water-soluble glucans.

S-glucan [( $\mathrm{I} \rightarrow 3)-\alpha$-glucan] was determined as the glucan extracted from the wall fraction with I M-KOH $\left(20 \mathrm{~min}, 60^{\circ} \mathrm{C}\right.$ ) and precipitated by adding acetic acid to the extract to $\mathrm{pH} 5$.

R-glucan $[(\mathrm{I} \rightarrow 3)-\beta,(\mathrm{I} \rightarrow 6)-\beta$-glucan] was extracted from the wall residue after $\mathrm{S}$-glucan extraction with $0.5 \mathrm{M}-\mathrm{HCl}\left(100^{\circ} \mathrm{C}, \mathrm{I} \mathrm{h}\right)$ followed by I $\mathrm{M}-\mathrm{KOH}\left(20 \mathrm{~min}, 60^{\circ} \mathrm{C}\right)$. All glucan fractions were quantified with the anthrone reagent (Fairbairn, 1953).

Chitin was determined by hydrolysis of the residue remaining after S-glucan and R-glucan extraction with $6 \mathrm{M}-\mathrm{HCl}\left(120^{\circ} \mathrm{C}, 2 \mathrm{~h}\right)$ and estimating the glucosamine content of the hydrolysate using the method of Johnson (1971).

Enzymic analysis. A crude R-glucanase preparation was isolated from the culture filtrate of $S$. commune strain $\mathrm{K} 8$ as described by Wessels (1969). Exo-(I $\rightarrow 3)-\beta$-glucanase was purified from the culture filtrate of the basidiomycete QM806 (Sietsma \& Wessels, 1977). The culture filtrate of $S$. commune was tested for R-glucanase activity using an R-glucan/chitin preparation from strain 699 as a substrate. The R-glucan from strain 699 is very similar to that of the dikaryon $699 \times 845$ (Sietsma \& Wessels, 1977).

The enzymic assays were done in $\mathrm{I} \mathrm{ml} 0.05 \mathrm{M}$-sodium acetate buffer $\mathrm{pH} 5.8$ containing either $0.5 \mathrm{mg}$ enzyme or $0.5 \mathrm{ml}$ culture filtrate and to $\mathrm{mg} \mathrm{R}$-glucan (added as R-glucan/chitin or as cell walls); incubation was at $35^{\circ} \mathrm{C}$ for $\mathrm{I} \mathrm{h}$. The reaction was stopped by adding $\mathrm{I} \mathrm{ml} 0.15 \mathrm{M}-\mathrm{Ba}(\mathrm{OH})_{2}$ and $\mathrm{I} \mathrm{ml} 5 \%(\mathrm{w} / \mathrm{v}) \mathrm{ZnSO}_{4}$. The precipitate was sedimented by centrifuging and the supernatant was tested for solubilized anthronepositive materials.

\section{RESULTS}

When $S$. commune $699 \times 845$ was grown in air, numerous primordia were produced after 6 days growth. At that time only I to $2 \%$ of the glucose in the medium was left (Table 2 ). When the cultivation time was extended to 12 days some of the fruit body primordia expanded, that is the pilei attained their final size and form by unilateral growth of the hymenial surface. However, when the organism was grown in air containing $5 \% \mathrm{CO}_{2}$, a thick mycelial mat was formed with aerial hyphae obscuring any fruit body primordia. Fullgrown fruit bodies were not observed. Again, after 6 days growth the glucose in the medium was virtually exhausted (Table 2). Wessels $(1965$, 1966) has shown that one of the prerequisites for pileus formation is a depletion of the carbon source in the medium; he also established a close relationship between normal pileus formation and R-glucan degradation by the enzyme R-glucanase. Table I shows that less R-glucan but more mucilage was formed when cultures were grown in $\mathrm{CO}_{2}$-enriched air. During glucose starvation, the amount of mucilage decreased both in $\mathrm{CO}_{2}$-grown and in air-grown cultures but the amount of R-glucan only decreased in the air-grown cultures. In both types of cultures the amounts of S-glucan and chitin hardly changed during starvation. 
Table 1. Carbohydrate material produced by Schizophyllum commune strain $699 \times 845$ during growth in an atmosphere of air or air plus $5 \% \mathrm{CO}_{2}$

The glucans are expressed as $\mathrm{mg}$ anhydroglucose per culture and chitin as $\mathrm{mg}$ anhydro-acetylglucosamine per culture.

Culture conditions

6 days, air

6 days, air $+5 \% \mathrm{CO}_{2}$

12 days, air

12 days, air $+5 \% \mathrm{CO}_{2}$
Carbohydrate material

$\begin{array}{rccc}\text { Mucilage } & \text { S-glucan } & \text { R-glucan } & \text { Chitin } \\ 77.9 & 27.3 & 57.6 & 4.8 \\ 146.1 & 19.7 & 24.8 & 5.3 \\ 24.4 & 27.2 & 19.2 & 5.0 \\ 56.7 & 21.7 & 22.9 & 5.2\end{array}$

Table 2. Residual glucose and R-glucanase activity in the culture filtrate of Schizophyllum commune strain $699 \times 845$ after cultivation under the specified conditions

R-glucanase activity is expressed as $\mu \mathrm{g}$ glucose equivalents liberated from $\mathbf{R}$-glucan/chitin of strain $699 \mathrm{~h}^{-1}(\mathrm{ml} \text { medium })^{-1}$.

$\begin{array}{lcc}\text { Culture conditions } & \begin{array}{c}\text { Residual } \\ \text { glucose } \\ (\%)\end{array} & \begin{array}{c}\text { R-glucanase } \\ \text { activity }\end{array} \\ 6 \text { days, air } & 1 \cdot 25 & 10 \\ 6 \text { days, air }+5 \% \mathrm{CO}_{2} & 1 \cdot 58 & 12 \\ 12 \text { days, air } & 0.02 & 168 \\ 12 \text { days, air }+5 \% \mathrm{CO}_{2} & 0.02 & 212\end{array}$

Table 3. Activity of R-glucanase from Schizophyllum commune $\mathrm{K} 8$ and $(\mathrm{I} \rightarrow 3)-\beta$-glucanase from QM806 on cell walls and R-glucans isolated from Schizophyllum commune $699 \times 845$ cultivated under the specified conditions.

All incubation mixtures, whether containing cell walls or the R-glucan derived from these walls, contained the same amount of $\mathrm{R}$-glucan $\left(10 \mathrm{mg} \mathrm{ml}^{-1}\right)$. The susceptibility is expressed as $\mu \mathrm{g}$ glucose equivalents released by the enzyme preparations (see Methods).

\begin{tabular}{|c|c|c|c|c|c|}
\hline \multirow[b]{3}{*}{ Culture conditions } & \multirow{3}{*}{$\begin{array}{l}\text { S-glucan/ } \\
\mathrm{R} \text {-glucan } \\
\text { ratio } \\
\text { in the wall }\end{array}$} & \multicolumn{4}{|c|}{ Susceptibility to: } \\
\hline & & \multicolumn{2}{|c|}{ R-glucanase } & \multicolumn{2}{|c|}{$(\mathrm{I} \rightarrow 3)-\beta$-glucanase } \\
\hline & & Walls & R-glucan & Walls & R-glucan \\
\hline $\begin{array}{l}6 \text { days, air } \\
6 \text { days, air }+5 \% \mathrm{CO}_{2}\end{array}$ & $\begin{array}{l}0.47 \\
0.80\end{array}$ & $\begin{array}{r}204 \\
76\end{array}$ & $\begin{array}{l}45 I \\
21 I\end{array}$ & $\begin{array}{r}127 \\
47\end{array}$ & $\begin{array}{l}521 \\
286\end{array}$ \\
\hline I 2 days, air & $I \cdot 42$ & 38 & I 87 & 6I & 3 II \\
\hline I 2 days, air $+5 \% \mathrm{CO}_{2}$ & 0.95 & 34 & 237 & 54 & 399 \\
\hline
\end{tabular}

In both cultures the enzyme R-glucanase was produced after the glucose in the medium had been exhausted (Table 2). This means that the higher $\mathrm{CO}_{2}$ pressure did not suppress R-glucanase production, thus excluding the possibility that the lack of R-glucan degradation in vivo was caused by absence of the enzyme. Another possibility was that the R-glucan in the walls of $\mathrm{CO}_{2}$-grown cultures was less susceptible to enzymic breakdown. This is suggested by the data of Table 3 which show that walls and R-glucan isolated from 6-day-old $\mathrm{CO}_{2}$-grown cultures were less sensitive to both $\mathrm{R}$-glucanase and $(\mathrm{I} \rightarrow 3)$ - $\beta$-glucanase than were walls and R-glucan from 6-day-old cultures grown in air. However, at 12 days the susceptibilities of walls and R-glucans from air-grown cultures and from $\mathrm{CO}_{2}$-grown cultures were both low.

If the effect of $\mathrm{CO}_{2}$ on pileus formation is mediated by a change in the enzymic susceptibility of R-glucan in the preformed mycelium, then $\mathrm{CO}_{2}$ must act before any fruit bodies are produced. To test this, 6-day-old agar cultures grown in air were transferred to an 
atmosphere of air plus $5 \% \mathrm{CO}_{2}$ and incubation was continued for another 6 days. The growth of the pilei was not inhibited. However, when $\mathrm{CO}_{2}$-grown cultures were transferred after 6 days to an atmosphere without $\mathrm{CO}_{2}$, no full-grown fruit bodies formed.

High temperature $\left(33^{\circ} \mathrm{C}\right)$ also inhibits fruiting in $S$. commune grown in air (Wessels, I 965). However, when agar cultures were cultivated at $33{ }^{\circ} \mathrm{C}$ in an atmosphere without any $\mathrm{CO}_{2}(\mathrm{KOH}$ pellets in the lid of the Petri dish), normal fruit bodies formed. Thus the effect of elevated temperature may actually be due to high $\mathrm{CO}_{2}$ tensions in the culture as a result of increased growth rate.

\section{DISCUSSION}

If one supposes that the primary effect of $\mathrm{CO}_{2}$ on the metabolism of Schizophyllum mycelium is basically the same as proposed for the self-inhibition of the A. bisporus spore by $\mathrm{CO}_{2}$ (Rast et al., $1976 a, b$ ), then in the cultures grown in $\mathrm{CO}_{2}$-enriched air more of the glucose taken up should be channelled into non-glycolytic pathways, such as polysaccharide synthesis. Table I shows that $\mathrm{CO}_{2}$-grown cultures do produce more glucan but this relates only to the mucilage.

The results also show that $\mathrm{CO}_{2}$ inhibits the breakdown of R-glucan, which normally accompanies pileus formation. No effect on R-glucanase production was found, but $\mathrm{CO}_{2}$ appears to decrease the susceptibility of R-glucan towards hydrolytic enzymes. Extraction of S-glucan greatly enhances the activity of the enzymes on the R-glucan/chitin complex, particularly when the S-glucan to R-glucan ratio is high (Table 3). However, the major effect of $\mathrm{CO}_{2}$ does not seem to be an increase in the protection of R-glucan by other polymers but rather on the enzymic susceptibility of the R-glucan itself.

Since the total amount of glucan (R-glucan plus mucilage) broken down in the presence or absence of added $\mathrm{CO}_{2}$ is about the same, it follows that the in situ degradation of the wallbound R-glucan is crucial for the support of pileus growth. That $\mathrm{CO}_{2}$ affects the susceptibility of R-glucan to enzymes as it is synthesized explains why $\mathrm{CO}_{2}$ had no effect when present only during pileus growth (Schwalb, I97I; this paper).

Using another dikaryon (K8), it was previously noted that elevated temperature has the same effects as described for $\mathrm{CO}_{2}$ in this paper, i.e. inhibition of degradation of R-glucan in vivo, no effect on R-glucanase formation and decreased susceptibility of the walls (Wessels, 1965, 1966). Therefore, the effect of elevated temperature may actually be due to high $\mathrm{CO}_{2}$ tensions in the cultures arising because of increased catabolism of glucose. This contention is supported by the fact that normal fruit bodies are produced at $33{ }^{\circ} \mathrm{C}$ if the $\mathrm{CO}_{2}$ produced metabolically is trapped in $\mathrm{KOH}$ (Schwalb, I97I; this paper).

The action of $\mathbf{R}$-glucanase on the $\mathbf{R}$-glucan releases mainly large soluble glucan fragments consisting of $(\mathrm{I} \rightarrow 3)$ - $\beta$-linked chains with side branches bearing $(\mathrm{I} \rightarrow 6)$ - $\beta$-linked glucose molecules (Wessels, I969; Sietsma \& Wessels, I 977). Exo-(I $\rightarrow 3)-\beta$-glucanase removes these $(\mathrm{I} \rightarrow 3$ )- $\beta$-linked chains from the R-glucan by sequential hydrolysis starting at the nonreducing end (Sietsma \& Wessels, 1977). Both enzymes leave a resistant glucan core that is closely associated with chitin. This may be the reason why the residual R-glucan left after in vivo degradation in air-grown cultures (Table 3, 12 days in air) is much less susceptible to $\mathrm{R}$-glucanase and ( $\mathrm{I} \rightarrow 3$ )- $\beta$-glucanase than the non-degraded $\mathrm{R}$-glucan (6 days in air). The insensitivity of $\mathrm{R}$-glucan from $\mathrm{CO}_{2}$-grown cultures to $\mathrm{R}$-glucanase and $(\mathrm{I} \rightarrow 3)$ - $\beta$-glucanase may indicate that, in these cultures, the glucanase-sensitive part of R-glucan was either not synthesized or not attached to the resistant core. The latter possibility seems particularly attractive because the mucilage that is excreted more abundantly in the $\mathrm{CO}_{2}$-grown cultures (Table $I)$ is structurally similar to the $(I \rightarrow 3)-\beta$-glucanase-sensitive part of the R-glucan (Sietsma \& Wessels, 1977).

In summary, our results show that $\mathrm{CO}_{2}$ indirectly affects the growth of the pilei of $S$. commune by changing the wall composition during the growth period. They do not 
exclude the possibility that $\mathrm{CO}_{2}$ also has an effect on earlier stages of fruit body formation. Because $\mathrm{CO}_{2}$ promotes the formation of a thick mat of aerial hyphae it is difficult to clarify this point.

The research of one of us (D.R.) is supported by the Swiss National Science Foundation (grant no. 3.1630.73).

\section{REFERENCES}

BACHOFEN, R. \& RAST, D. (1968). Carboxylierungsreaktionen in Agaricus bisporus. III. Pyruvat und Phosphoenolpyruvat als $\mathrm{CO}_{2}$-Acceptoren. Archiv für Mikrobiologie 60, 2 1 7-234.

FaIRBaIRN, N. J. (1973). A modified anthrone reagent. Chemistry and Industry 72, 86.

Johnson, A. R. (1971). An improved method of hexosamine determination. Analytical Biochemistry 44, 628-635.

Kitamoto, Y. \& Gruen, H. E. (1976). Distribution of cellular carbohydrates during development of the mycelium and fruitbodies of Flammulina velutipes. Plant Physiology 58, 485-491.

Nieder Pruem, D. J. (1963). Role of carbon dioxide in the control of fruiting of Schizophyllum commune. Journal of Bacteriology 85, I 300-I 308.

RAST, D. \& BACHOFEN, R. (1967). Carboxylierungsreaktionen in Agaricus bisporus. I. Der endogene $\mathrm{CO}_{2}$-Acceptor. Archiv fiir Mikrobiologie 57, 392-405.

Rast, D., Stäuble, E. J. \& Zobrist, P. (I976a). The Krebs cycle and control of dormancy in the Agaricus bisporus spore. New Phytologist 76, 469-477.

RAST, D., Greuter, B., LendenManN, J. \& Zobrist, P. $(1976 b)$. The biochemistry of dormancy and germination in the Agaricus bisporus spore. Mushroom Science 9, 59-75.

Schwalb, M. N. (197I). Commitment to fruiting in synchronously developing cultures of the basidiomycete Schizophyllum commune. Archiv für Mikrobiologie 79, $102-107$.

Sietsma, J. H. \& Wessels, J. G. H. ( I977). Chemical analysis of the hyphal wall of Schizophyllum commune. Biochimica et biophysica acta 496, 225-239.
TABER, W. A. (1966). Morphogenesis in Basidiomycetes. In The Fungi, vol. II, pp. 387-412. Edited by G. C. Ainsworth and A. S. Sussman. New York: Academic Press.

TsChierPe, J. H. \& Sinden, J. W. (1964). Weitere Untersuchungen über die Bedeutung von Kohlendioxyd für die Fruktifikation des Kulturchampignons Agaricus campestris var. bisporus (L). Lge. Archiv für Mikrobiologie 49, 405-425.

Wessels, J. G. H. (1965). Morphogenesis and biochemical processes in Schizophyllum commune Fr. Wentia 13, I-I I3.

Wessels, J. G. H. (1966). Control of cell wall glucan degradation during development in Schizophyllum commune. Antonie van Leeuwenkoek 32, 341355.

WESSELS, J. G. H. (1969). A $\beta$-I,6-glucan glucanohydrolase involved in hydrolysis of cell-wall glucan in Schizophyllum commune. Biochimica et biophysica acta 178, 191-193.

Wessels, J. G. H. \& Marchant, R. (1974). Enzymic degradation of septa in hyphal wall preparations from a monokaryon and a dikaryon of Schizophyllum commune. Journal of General Microbiology 83, 359-369.

Wessels, J. G. H. \& Niederpruem, D. J. (1967). Role of a cell-wall glucan-degrading enzyme in mating of Schizophyllum commune. Journal of Bacteriology 94, I 594-I602.

Wessels, J. G. H., Kreger, D. R., Marchant, R. Regensburg, B. A. \& DE VRIES, O. M. H. (1972). Chemical and morphological characterization of the hyphal wall surface of the basidiomycete Schizophyllum commune. Biochimica et biophysica acta 273, 346-358. 